\title{
EFICIÊNCIA DA PRODUÇÃO DE UVAS PARA MESA EM PEQUENAS PROPRIEDADES RURAIS: APLICAÇÃO DE ANÁLISE ENVOLTÓRIA DE DADOS
}

\author{
Adriana de Souza Colombo ${ }^{1}$ \\ Karina Souza Batista ${ }^{2}$ \\ Omar Jorge Sabbag ${ }^{3}$
}

\section{RESUMO}

A uva é uma fruta de grande importância econômica nacional. O Estado de São Paulo é o principal produtor de uva para mesa. Para a região Noroeste do Estado, a viticultura mostra-se como uma atividade proeminente, sobretudo para os pequenos produtores rurais. Analisar o desempenho de unidades de produção afeta 0 processo decisório, principalmente quando se consideram variantes de cunho financeiro e não financeiro. Este trabalho objetivou avaliar a eficiência técnica de onze unidades produtoras de uvas de Jales/SP em 2015. Foi utilizado como instrumento analítico a Análise Envoltória de Dados (Data Envelopment Analysis $D E A)$ que se fundamenta na programação linear para identificar os produtores mais eficientes na utilização dos insumos. Os cálculos foram realizados com o auxílio do software DEAP versão 2.1. Os resultados da pesquisa apontam quatro unidades produtoras com máxima eficiência. Duas DMU's (decision making units) apresentaram excessos de insumos, operando em escala supra-ótima. Os resultados também demostram que uma proporção significativa das propriedades são ineficientes tecnicamente. No que tange ao agronegócio, a aplicação da ferramenta DEA vem se difundindo devido sua característica de proporcionar aos produtores subsídios para gestão e possibilidade de buscar a melhoria contínua de seus processos.

Palavras-chave: benitaka, desempenho, niágara rosada, viticultura.

\section{FINE TABLE GRAPES PRODUCTION EFFICIENCY SMALL PROPERTIES RURAL: DATA ENVELOPMENT ANALYSIS APPLICATION}

\begin{abstract}
The grape is a fruit of great national economic importance. The São Paulo state is the main grape producer table. For the Northwest region, viticulture shows up as a prominent activity, especially for small farmers. Analyze the performance of

\footnotetext{
${ }^{1}$ Graduada em Agronomia (UNESP). Mestrado em Agronomia (UNESP) e Doutoranda em Agronomia (UNESP). E-mail: adriana.colombo@fatec.sp.gov.br

${ }^{2}$ Graduada em Ciências Contábeis (AEMS). Especialização em Contabilidade Avançada pela Universidade de Jacarepaguá E-mail: ksb_nina@hotmail.com

3 Docente do Departamento de Fitotecnia, Tecnologia de Alimentos e Sócioeconomia (DFTASE), FEIS/UNESP. Área: Economia e Gestão do Agronegócio. E-mail: sabbag@agr.feis.unesp.br
} 
production units affects the decision-making process, especially when considering financial nature variants and non-financial. This study aimed to evaluate the technical efficiency of eleven mills grape Jales/SP in 2015. It was used as an analytical tool Data Envelopment Analysis (DEA) which is based on linear programming to identify the most efficient producers in use of inputs. The calculations were performed with the help of DEAP software version 2.1. The survey results suggest four production units with maximum efficiency. Two DMU's (decision making units) showed excesses of inputs, operating at supra-optimal scale. The results also demonstrate that a significant proportion of the properties are technically inefficient. With regard to agribusiness, the application of DEA tool is spreading due to its characteristic of providing subsidies to producers for management and the ability to seek continuous improvement of its processes.

Keywords: benitaka, niagara rosada, performance, viticulture.

\section{INTRODUÇÃO}

Mundialmente, a uva é umas das frutas mais consumidas, sendo em sua forma in natura (mesa) ou sob processamento (sucos e vinhos). O Brasil é um grande país produtor de uvas, onde a área plantada com videira, segundo dados do IBGE (2015), é de 80.350 hectares, sendo aproximadamente $90 \%$ da produção oriunda da região Sul se destina à produção de vinhos, enquanto nas regiões Sudeste e Nordeste predominam a produção de uvas de mesa.

Fruta de grande relevância econômica nacional, no Brasil foram produzidas 1.437.245 toneladas de uvas em 2014. Levantamentos do IBGE apontam que houve uma redução da área plantada em 0,25\% entre 2014 e 2015; entretanto, a safra brasileira de 2015 deverá ser 4,76\% superior à 2014 .

Mello (2015) aponta que o Estado de São Paulo foi o maior produtor de uva para mesa do Brasil em 2013, produzindo 149,05 mil toneladas. De acordo com o Instituto de Economia Agrícola (IEA), em 2015 no Estado, a viticultura de uvas finas de mesa se concentrou nas áreas de atuação dos Escritórios de Desenvolvimento Rural (EDR's) de Campinas, Itapetininga e Jales (que produzem uvas finas e rústicas).

A região Noroeste do Estado de São Paulo, a viticultura tem-se apresentado como uma atividade importante para os produtores rurais, sobretudo aqueles detentores de pequenas áreas. Nos anos 80 e 90, a região surgiu como polo produtor de uvas, alcançando destaque no abastecimento nacional de uvas finas.

A produção de uvas finas para mesa (Vitis vinifera) na localidade, é representada, principalmente, por cultivares como a Itália e suas mutações (Rubi e Benitaka), enquanto a principal representante das uvas comuns ou rústicas para mesa (Vitis labrusca) é a cultivar Niágara Rosada. Em 2005, a área sob exploração da uva na região de Jales foi de 1.091,4 hectares distribuídos entre 951,2 hectares para as variedades de uvas finas de mesa e 140,2 hectares com uvas rústicas (COSTA et al., 2008).

Diante do exposto, analisar a eficiência de unidades de produção afeta diretamente ao processo decisório, principalmente quando se consideram variáveis de natureza financeira e não financeira. Esta pesquisa utilizou a Análise Envoltória de Dados (DEA), por meio da modelagem BCC, proposto por Banker, Charnes e Cooper (1984), que pressupõem a imposição de tecnologia com retornos constantes 
de escala e admite que o conjunto de produção apresente retornos variáveis de escala (SOUZA; WILHELM, 2009).

Neste contexto, utilizando a metodologia não paramétrica DEA, o presente trabalho tem como objetivo medir e analisar a eficiência técnica de viticultores de pequenas propriedades rurais de Jales/SP.

\section{A VITICULTURA NO NOROESTE PAULISTA}

A videira, na região de Jales, foi introduzida pelo agricultor Massaharu Nagata, em meados de 1965. Interessado em diversificar a produção de sua propriedade, basicamente voltada à cafeicultura e avicultura, o mesmo trouxe de Mogi das Cruzes/SP as primeiras estacas de modo experimental (NETO et al., 2009). Desde então iniciaram-se os plantios e as adaptações da cultura para a região. No fim da década de 80 e início da década de 90, devido as técnicas de manejo especificamente empregadas as condições edafoclimáticas da região, a viticultura tomou força e despontou, transformando a região num polo de relevante expressão econômica, alcançando participação destacada no abastecimento nacional.

De acordo com o Levantamento das Unidades de Produção Agropecuária do Estado de São Paulo - LUPA (2008), o EDR de Jales é composto por 22 municípios que ocupam, aproximadamente, 319.420,4 hectares e 9.464 propriedades agrícolas. Só o município de Jales abrange 1.248 propriedades que ocupam 33.542,2 hectares. Tal região é a segunda maior em importância na produção de uvas de mesa do Estado (COSTA et al., 2008).

Para o noroeste paulista, a viticultura é uma atividade de extrema importância econômica e social, dada a predominância de pequenas propriedades rurais. Esta região apresenta uma característica peculiar e vantajosa para a produção, visto que o clima quente associado ao uso de tecnologias permite a comercialização em meses de entressafra das outras importantes regiões produtoras (HIGA, 2002). Os mercados mais frequentes para os quais são destinadas as uvas de mesa produzidas na região de Jales, é o entreposto de abastecimento Ceasa e a central terminal Ceagesp.

A mão de obra utilizada na produção é predominantemente familiar. Ainda, associa-se ao sistema de parceria de meação que é disseminado entre os produtores. Este sistema favorece a produtividade pois, o parceiro necessita produzir da melhor forma para que seu rendimento seja alto, e a mão de obra familiar tende a ser mais cuidadosa no manejo das uvas (COSTA et al., 2008).

A viticultura na região tem mostrado condições de gerar renda e de manter os produtores no campo em função da produtividade e do preço da uva no mercado.

\section{ANÁLISE ENVOLTÓRIA DE DADOS}

$\mathrm{Na}$ busca de melhores estratégias de competitividade, muitas empresas almejam eficiência técnica de escala e alocativa. Isso corresponde ao menor uso dos insumos com o nível de produção adequado, aliado ao menor custo e maior receita (FERREIRA; GOMES, 2012).

A ferramenta matemática que mede a eficiência das unidades produtivas é a Análise de Envoltória de Dados (do inglês Data Envelopment Analysis - DEA). Para estudos com DEA, torna-se necessário, o entendimento sobre eficiência. Mello et al. (2005), apontam que eficiência é um conceito relativo, comparando o que foi produzido, diante dos recursos disponíveis, com o que poderia ter sido produzido 
com os mesmos recursos. Normalmente, para avaliar o que poderia ser produzido são utilizadas médias, em métodos chamados de paramétricos.

Para Arzubi e Berbel (2002) a análise DEA possibilita a comparação das empresas ineficientes com as eficientes, também chamadas de benchmarks. Desta forma, são proporcionadas informações uteis para decisões nas empresas ineficientes, de forma a otimizar o uso dos recursos e maximizar a produção.

Ferreira e Gomes (2012) denominam cada empresa ou organização produtiva como DMU (unidades tomadoras de decisão - Decision Making Units). A análise de eficiência de unidades produtivas é uma ferramenta importante tanto para fins estratégicos, onde se compara unidades produtivas, quanto para 0 planejamento, avaliando-se resultados do uso de diferentes combinações de fatores. Também é uma ferramenta para a tomada de decisão, visando melhorar o desempenho da DMU, por meio da análise da distância entre a produção atual e potencial, identificando onde é melhor investir (GOMES; MANGABEIRA; MELLO, 2005).

\section{MATERIAL E MÉTODOS}

A abrangência do estudo compreendeu a área do município de Jales, localizado no noroeste do Estado de São Paulo, com coordenadas geográficas $20^{\circ}$ 16' 6" Latitude Sul e $50^{\circ} 32$ ' 56" Longitude Oeste e 486 metros de altitude. O município e seu entorno têm como característica o predomínio de pequenos estabelecimentos rurais, da agricultura familiar e da diversificação agrícola (NARDOQUE, 2007). Dentre as principais lavouras em área plantada em Jales, temse: Iaranja (1.100 ha), seringueira (300 ha), banana (250 ha), eucalipto (250 ha), milho (200 ha) e uvas (281 ha) (IBGE, 2014).

As propriedades que cultivam uva no município de Jales se caracterizam pela estrutura fundiária, onde prevalecem as pequenas propriedades e a mão de obra familiar. No município, a colheita ocorre normalmente entre os meses de julho e outubro, correspondente à entressafra de outras regiões. Isso favorece o alcance de preços superiores aos obtidos nas demais regiões vitícolas do estado, como Jundiaí, São Miguel Arcanjo e Indaiatuba, onde a colheita acontece entre os meses de novembro e março (CONCEIÇÃO; TONIETTO, 2012).

Para o levantamento de dados primários desta pesquisa, foram aplicados formulários para onze produtores de uva do município de Jales/SP. Segundo Marcone e Lakatos (2010) o formulário é um dos instrumentos essenciais para a investigação social, cujo sistema de coleta de dados consiste em obter informações diretamente do entrevistado. Os produtores analisados foram escolhidos aleatoriamente, havendo como critério de escolha o cultivo das variedades Niágara Rosada ou Benitaka. Convém destacar que a variedade Benitaka é considerada uva fina de mesa, sendo uma mutação da uva Itália. É exigente em tratos culturais e apresenta sensibilidade a pragas e doenças (SOUZA; MARTINS, 2002). Já a variedade Niágara Rosada é uma variedade rústica (BOLIANI et al., 2008), possui mediana resistência às doenças fúngicas, apresenta médio vigor, mas tem o desempenho melhorado quando bem adubada.

Nesta pesquisa foi utilizada a Análise Envoltória de Dados, método que vem sendo utilizado para mensurar a eficiência relativa de unidades produtivas. $O$ número amostral de unidades analisadas (DMU's) - onze no total - é suficiente para o número de variáveis avaliadas (dois inputs e dois outputs), pois de acordo com Ali e Seiford (1993), o número de unidades de produção deve ao mínimo resultar em duas vezes o número de insumos $(X)$ e produtos $(Y)$, sendo o número de unidades necessárias $>2(X+Y)$, assim estando condizente com o presente estudo. Definiu- 
se, para esta pesquisa, que o modelo seria composto por quatro variáveis, ou seja, considerando-se o tamanho da amostra de unidades produtoras (DMU's), mantendose a proporção de produtores analisados. Deve ainda constituir certa homogeneidade entre elas, por utilizarem insumos semelhantes para produzirem os mesmos e terem certa autonomia na tomada de decisão, encaixando-se perfeitamente nas definições de DMU's a serem analisadas pela técnica DEA.

Para o estabelecimento do modelo, foram necessárias duas matrizes de dados, uma contendo os insumos e outra relacionada com produtos. A matriz $\mathrm{X}$ de insumos, de ordem $(k \times n)$, foi composta por insumos, utilizados por número de produtores. Já a matriz $\mathrm{Y}$ de produtos, ordem $(\mathrm{m} \times \mathrm{n})$ foi composta por $\mathrm{m}$ produtos, produzidos pelos $n$ produtores. No caso deste trabalho, considerando a produção anual de uvas, foram utilizadas quatro variáveis, sendo dois outputs $(m=2)$, referente à renda da cultura ( $\mathrm{R} \$ / \mathrm{ano})$ e produtividade $(\mathrm{kg} / \mathrm{planta})$, e dois inputs $(\mathrm{k}=2)$, sendo número de plantas e irrigação (horas/semana).

Foi atribuído o modelo BCC, também chamado de VRS (Variable Returns to Scale), que considera situações de eficiência de produção com variação de escala e não assume proporcionalidade entre inputs e outputs. $\mathrm{Na}$ apresentação da formulação do problema de programação fracionária, previamente linearizado, para esse modelo (BANKER et al., 1984), $h_{0}$ é a eficiência da $\mathrm{DMU}_{0}$ em análise; $x_{i k}$ representa o input $i$ da $\mathrm{DMU}_{k}, y_{j k}$ representa o output $j$ da $\mathrm{DMU}_{k} ; v_{i}$ é o peso atribuído ao input $i, u_{j}$ é o peso atribuído ao output $j ; u^{*}$ é um fator de escala.

$$
\begin{aligned}
& \max h_{o}=\sum_{j=1}^{m} u_{j} y_{j o}+u^{*} \\
& \text { sujeito a } \\
& \sum_{i=1}^{n} v_{i} x_{i o}=1 \\
& \sum_{j=1}^{m} u_{j} y_{j k}-\sum_{i=1}^{n} v_{i} x_{i k} \leq 0, \quad k=1, \ldots, s \\
& u_{j}, v_{i} \geq 0 \quad \forall x, y \\
& u^{*} \in \mathfrak{R}
\end{aligned}
$$

A orientação da análise foi input, ou seja, para os insumos em que o objetivo é manter a produção na mesma magnitude e otimizar o uso dos recursos. Após a coleta de dados, estes foram tabulados em plataforma Excel, sendo utilizado o software DEAP v.2.1, base MS-DOS ${ }^{4}$, desenvolvido por Coelli (1996).

\section{RESULTADOS E DISCUSSÃO}

Na Tabela 1 são apresentadas as estatísticas descritivas das variáveis de análise de eficiência das unidades produtoras de uva em Jales/SP. Os resultados apresentam uma renda média das propriedades de $\mathrm{R} \$ 208.427,00$ e produtividade variando de 7 a $48 \mathrm{~kg} /$ planta. A grande amplitude de valores entre inputs-outputs justifica a variabilidade entre as classes de eficiência.

\footnotetext{
${ }^{4}$ D.O.S., sigla para Disk Operating System ou sistema operacional em disco. É um acrônimo para vários sistemas operativos intimamente relacionados para computadores entre 1981 e 1995 (FLYNN, 2001, p.13).
} 
Tabela 1 - Estatística descritiva das variáveis de unidades produtoras de uva por ciclo, Jales/SP, 2015.

\begin{tabular}{llllll}
\hline Variáveis & Unidade & Média & $\begin{array}{l}\text { Desvio } \\
\text { Padrão }\end{array}$ & Mínimo & Máximo \\
\hline Renda da Prop. (O1) & $\mathrm{R} \$$ & $208.427,00$ & $268.264,10$ & $14.000,00$ & $738.000,00$ \\
Produtividade (O2) & $\mathrm{kg} /$ planta & 26,09 & 14,92 & 7 & 48 \\
Plantas (I1) & Número & $3.282,72$ & $4.593,87$ & 100 & 15.000 \\
Irrigação (I2) & hs/semana & 15,38 & 10,25 & 2,7 & 40 \\
\hline
\end{tabular}

O1 e O2 (outputs 1 e 2); I1 e I2 (inputs 1 e 2).

Fonte: Resultados da pesquisa.

A discrepância entre a renda das propriedades (O1) fica evidente, onde o valor máximo $(R \$ 738.000,00)$ é quase 53 vezes superior ao valor mínimo, $\mathrm{R} \$ 14.000,00$. Esta observação pode ser justificada principalmente devido a diferença de gerenciamento entre as DMU's analisadas e a importância que a cultura representa para cada organização produtiva. A quantidade produzida nestas unidades também é um fator que influencia na renda obtida.

Vale ressaltar que padrões tecnológicos distintos resultam em rentabilidade variável, decorrente dos níveis distintos de produção e produtividade de cada produtor (SABBAG; COSTA, 2015).

Para os dados de produtividade (O2), o valor máximo de $48 \mathrm{~kg} / \mathrm{planta}$ é aproximadamente 7 vezes superior ao valor mínimo. Em trabalho sobre o cultivo da videira Niágara Rosada em regiões tropicais, Maia e Mello (2003) apontam para uma produtividade média de $16,5 \mathrm{~kg} / \mathrm{planta}$, a partir do $2^{\circ}$ ano de produção.

A variação entre o número de plantas (I1) também foi muito alta, oscilando de 100 plantas para uma unidade produtora a 15.000 plantas para outra. Entre os fatores que interferem na escolha do espaçamento, ressalta-se a variedade da copa e do porta enxerto, o sistema de condução, a topografia do terreno, máquinas disponíveis e a fertilidade do solo. O espaçamento mais comum em áreas tropicais varia de 2 a 5 metros entre linhas e 1,5 a 4 metros entre plantas. Com isso, 0 número de plantas pode variar de 500 a 3.333 plantas (BOLIANI; CORREA, 2001).

Para a cultivar Niágara Rosada conduzida no sistema de latada, o espaçamento entre linhas deve ser de $2,50 \mathrm{~m}$ a $3,00 \mathrm{~m}$, com 1,50m a 2,00m entre plantas. Utilizando o espaçamento de $2,75 \mathrm{~m}$ x 2,0m, serão obtidas cerca de 1.900 plantas por hectare, o que possibilita a mecanização com pequenos tratores e uso de irrigação por micro aspersão (MAIA; CAMARGO; NACHTIGAL, 2003).

A produção de uva exige grande conhecimento técnico, destacando-se a irrigação, o uso de reguladores vegetais e o sistema de podas fundamentais para a produção de frutas com qualidade e fora da época de produção de outras tradicionais regiões produtoras (COSTA et al., 2012).

Não foi detectado um padrão para a quantidade de horas de irrigação (I2) entre as propriedades, sendo que uma chegou a irrigar 40 horas em uma semana e outra não passou de 2,5 horas. A demanda hídrica da videira depende da variedade, do porta enxerto, do espaçamento entre as plantas, do tipo de sistema de condução, do uso de coberturas sobre o parreiral e da demanda hídrica atmosférica da região (BOLIANI; CORREA, 2001). A evapotranspiração da Niágara Rosada conduzida em 
sistema latada na região Noroeste do Estado de São Paulo foi de aproximadamente $3 \mathrm{~mm}$ por dia (CONCEIÇÃO; MANDARINI NETO; MAIA, 1999).

Considerando-se os diferentes estádios fenológicos da cultura, a evapotranspiração pode variar mais ou menos em função de alguns fatores, entre eles, a presença ou ausência de cobertura vegetal sobre o solo. Em área sem cobertura vegetal, a evapotranspiração variou de 1,0 (fase de desenvolvimento foliar) a 4,5 mm/dia (fase de desenvolvimento de frutos), com uma média de 2,3 $\mathrm{mm} /$ dia, enquanto que em área com cobertura vegetal, variou de 0,9 (fase de aparecimento das inflorescências) a $4,7 \mathrm{~mm} / \mathrm{dia}$ (fase de desenvolvimento de frutos) com uma média de $2,5 \mathrm{~mm} /$ dia (CONCEIÇÃO et al., 2012).

Para a produção de uvas rústicas em regiões tropicais, o sistema de irrigação mais utilizado tem sido a aspersão e micro aspersão, para os casos de condução por latada. Nos cultivos conduzidos com espaldeiras, verifica-se o maior uso de irrigação por gotejamento (BOLIANI; FRACARO; CORRÊA, 2008).

Segundo o Agrianual (2014), para o custo de produção da uva Niágara de $\mathrm{R} \$ 33.101,00$ em Jales/SP, referente ao segundo ano de produção, os gastos com irrigação representaram $14,9 \%$. Do $3^{\circ}$ ao $12^{\circ}$ ano, o custo se mantém em $\mathrm{R} \$ 14.727,00$, na qual a irrigação correspondeu a $18,3 \%$. Estes dados apontam para uma grande representatividade econômica desta operação, e mais uma vez justificam a importância de uma irrigação eficiente.

A Tabela 2 demonstra o ranking das propriedades viticultoras eficientes. Os resultados da pesquisa apresentam as DMU's 2, 3, 10 e 11 como sendo aquelas que operam em escala ótima de produção, sendo consideradas benchmarks, ou seja, pares de excelência para as demais unidades. Estas quatro propriedades eficientes $(36,36 \%$ da amostra) apresentam escore de eficiência $(\theta)$ igual a 100\%.

Tabela 2 - Ranking das propriedades viticultoras eficientes, Jales/SP, 2015.

\begin{tabular}{|c|c|c|c|c|c|}
\hline SEQ. & DMU & Cultivar & $\begin{array}{c}\text { Eficiência } \\
\text { Técnica CRS }\end{array}$ & $\begin{array}{c}\text { Eficiência } \\
\text { Técnica VRS }\end{array}$ & $\begin{array}{l}\text { Eficiência de } \\
\text { Escala }\end{array}$ \\
\hline \multirow{4}{*}{$1^{\circ}$} & 2 & Benitaka & 1,000 & 1,000 & 1,000 \\
\hline & 3 & Benitaka & 1,000 & 1,000 & 1,000 \\
\hline & 10 & Niágara & 1,000 & 1,000 & 1,000 \\
\hline & 11 & Niágara & 1,000 & 1,000 & 1,000 \\
\hline $2^{\circ}$ & 4 & Benitaka & 0,800 & 1,000 & 0,800 \\
\hline $3^{\circ}$ & 7 & Niágara & 0,729 & 1,000 & 0,729 \\
\hline $4^{\circ}$ & 6 & Benitaka & 0,743 & 0,827 & 0,899 \\
\hline $5^{\circ}$ & 5 & Benitaka & 0,625 & 0,736 & 0,850 \\
\hline $6^{\circ}$ & 1 & Benitaka & 0,347 & 0,605 & 0,574 \\
\hline $7^{\circ}$ & 9 & Niágara & 0,340 & 0,342 & 0,994 \\
\hline $8^{\circ}$ & 8 & Niágara & 0,215 & 0,261 & 0,825 \\
\hline
\end{tabular}

Fonte: Resultados da pesquisa.

Um produtor é tecnicamente eficiente quando a quantidade do seu produto é a máxima possível de se obter com os recursos de que dispõe. Segundo Reinaldo et al. (2002), a eficiência técnica é determinada pela diferença entre a proporção observada de quantidades combinadas de um produto de uma empresa com o insumo e a proporção alcançada pela melhor prática. 
Além de identificar as DMU's eficientes, os modelos DEA permitem medir e localizar a ineficiência e estimar uma função de produção linear por partes, que fornece o benckmark para as DMU's ineficientes. Esse benchmark é determinado pela projeção das DMU's ineficientes na fronteira de eficiência (MELLO et al., 2003). Segundo Pinheiro e Altafin (2007), os produtores referenciais, que possuem eficiência máxima nos sistemas produtivos, são denominados de benchmarks para os demais produtores em análise. De outro modo, a Análise Envoltória de Dados tem o objetivo de avaliar a eficiência relativa, comparando aos melhores padrões de eficiência (benchmarks), de uma amostra de organizações produtivas (FERREIRA; GOMES, 2012).

Por outro lado, a DMU 8, com a variedade Niágara Rosada, foi a com menor eficiência técnica global, sendo que para o output 2 (O2) a produção de 7 $\mathrm{kg} /$ planta deve ser de $21.089 \mathrm{kkg} /$ planta, potencializando o índice em 66,81\%. Da mesma forma, o número de plantas (I1) deve ser reduzido a 1.435 exemplares, em contraposição a 5.500, bem como o no de horas irrigadas semanais (I2) ser reduzido para 4,69 horas, ao invés de 18 horas, apresentando um consumo excessivo de insumos. Vale destacar que a DMU 8 pertence ao mesmo produtor que possui a DMU 3, sendo este eficiente no cultivo da variedade Benitaka. Neste sentido, esta unidade deve reorientar seu planejamento para reduzir o uso de insumos para a variedade Niágara Rosada, de maneira proporcional à produção obtida, em aproximadamente $74 \%$ para o output e o conjunto de inputs considerados, alcançando assim seu ponto na curva de eficiência.

Ainda assim, muita ineficiência também foi constatada na DMU 9, que cultiva a variedade Niágara Rosada, a qual obteve produção de $12 \mathrm{~kg} /$ planta (O2), quando deveria ter obtido $41.764 \mathrm{kkg} /$ planta. Este montante indica que operou com folga de $71,27 \%$ na variável output 2. São 6.000 plantas (I1) com 24 horas por semana de irrigação (I2), sendo que poderia alcançar a mesma produção com apenas 2.052 plantas com 8,2 horas de irrigação semanal, havendo a necessidade de redução das variáveis inputs em $65,8 \%$.

A terceira menos eficiente foi a DMU 1, com a variedade Benitaka, que produziu $18 \mathrm{~kg} /$ planta (O2), mas poderia ter alcançado o patamar de 31.299 $\mathrm{kg} /$ planta, o que representa uma folga na variável output 2 (produção/planta) de $44,27 \%$. Cultiva 555 plantas (I1), quando poderia possuir apenas 336 plantas. A irrigação (I2) poderia ser reduzida a 10,2 horas, em oposição a 17 horas semanais. Para esta DMU, existe a necessidade de redução em ambas as variáveis inputs em $39,53 \%$.

Estas informações sobre as DMU's eficientes ou ineficientes podem ser melhor expressados na Figura 1. Assim, tem-se a fronteira DEA-eficiente para o output 1 e o output 2. Para o output 1 , o eixo $x$ foi obtido pela razão entre o número de plantas e a renda da propriedade com a cultura; no eixo y, foi resultante da proporção entre o número de horas irrigadas por semana e a renda da propriedade com a cultura. Já para o output 2 , foi caracterizada para o eixo $x$ a razão entre 0 número de plantas e a produtividade, bem como o número de horas irrigadas por semana dividida pela produtividade, para o eixo $\mathrm{Y}$. A fronteira é formada então pelas unidades mais próximas dos eixos $\mathrm{X}$ e $\mathrm{Y}$. Pode-se observar que apenas as unidades 2, 3, 10 e 11 fazem parte da fronteira. Os pontos mais distantes do eixo do gráfico indicam as unidades menos eficientes, correspondendo às DMU's 8 e 9 respectivamente. 
Figura 1 - Fronteira eficiente no modelo com Output 1 e Output 2, Jales/SP, 2015.

OUTPUT 1

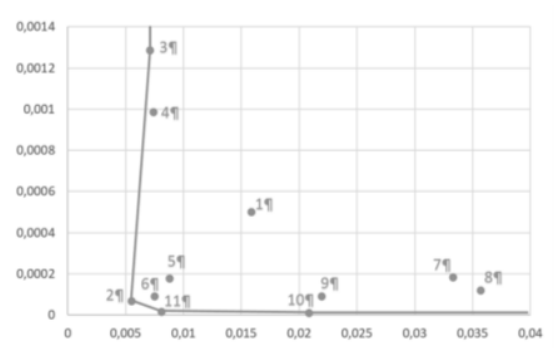

OUTPUT 2

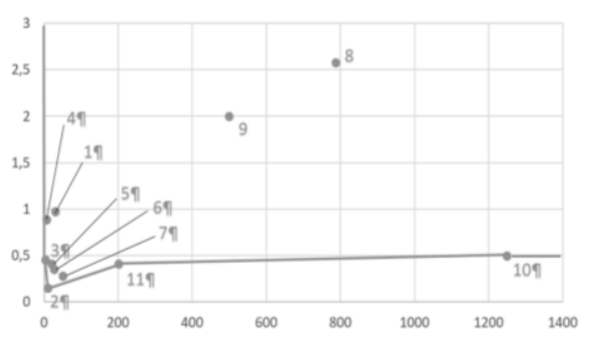

Fonte: Elaborado pelos autores.

Quanto à natureza de retornos, a Tabela 3 expõe o retorno à escala produtiva. Quando se analisa a eficiência de escala, têm-se que quatro DMU's $(36,36 \%)$ trabalharam com retornos constantes de escala, constituintes de excelência (benchmarks); cinco propriedades (45,46\%) apresentaram retornos crescentes de escala, significando que poderiam investir em insumos para serem mais eficientes e duas propriedades $(18,18 \%)$ apresentaram retornos decrescentes de escala, ou seja, operam com desperdício de insumos.

Neste caso, as DMU's 4 e 6 apresentaram excesso de insumos (inputs) em função dos dados de produção. Enquanto a DMU 4 apresentou escala de eficiência de 0,800, a DMU 6 apresentou 0,899. Todavia, a DMU 4 obteve eficiência técnica em $100 \%$ pelo modelo BCC, caracterizando-se como uma falsa eficiente.

Tabela 3 - Retorno à escala de produção, conforme análise das propriedades vitícolas, Jales/SP, 2015.

\begin{tabular}{lcc}
\hline Escala de Produção & $N^{\circ}$ de DMU's & $(\%)$ - Amostra \\
\hline Retornos constantes & 4 & 36,36 \\
Retornos crescentes & 5 & 45,46 \\
Retornos decrescentes & 2 & 18,18 \\
\hline Total & 11 & 100 \\
\hline
\end{tabular}

Fonte: Resultados da pesquisa.

Para a DMU 6 foi encontrada uma variável em desperdício. Por ter apresentado uma característica de rendimento decrescente, demonstrou a necessidade de diminuir em $22,25 \%$ as horas de irrigação. Também houve folga nesta DMU 6 em relação ao output 2 em 25,69\% e a necessidade de reduzir as variáveis input 1 (número de plantas) e input 2 (irrigação) em 20,97\% e 17,33\%, respectivamente.

$\mathrm{Na}$ viticultura da região Noroeste do Estado de São Paulo, Pelinson (2001) descreve que a utilização intensiva de mão de obra, irrigação, tratamento fitossanitário com grandes quantidades de fungicidas e altos custos de manutenção são as principais características do cultivo de uva, e que de certa forma, limitam a expansão da atividade. O receio de não produzir tem levado os produtores a 
aplicações excessivas de nutrientes. A não consideração dos resultados obtidos nas análises vem causando problemas relacionados ao excesso de nutrientes e desequilíbrio destes no solo (COSTA et al., 2012). A aplicação de fertilizantes e adubos sem a recomendação adequada e a compreensão completa de como estes vão afetar, em longo prazo, a fertilidade dos solos de sistema convencional em grandes áreas, é preocupante, e muitos destes nutrientes podem ser carreados até corpos d'água e causar poluições severas. O uso excessivo de fertilizantes fosfatados e nitrogenados causam a eutrofização de águas (DARILEK et al., 2009).

Ressalta-se que o tempo médio de experiência dos produtores com a cultura da uva foi de 17 anos, variando entre 6 a 27 anos, o que indica forte tradição regional com a atividade.

Por fim, a falta de mão de obra qualificada é um dos problemas apontados pelos produtores como fator limitante para expansão da cultura na região. Verifica-se que embora a atividade seja considerada como uma alternativa para agricultura familiar, esta tem exigido mão de obra mais especializada. Neste sentido, os produtores não contam com assistência técnica regular, não seguem recomendações de adubação e não empregam critérios técnicos para o manejo da irrigação. Assim, conforme Simonetti et al. (2013), percebe-se que o aumento da diversidade de renda ocorre nos estabelecimentos com maior disponibilidade de força de trabalho familiar, fazendo-se necessário esta condição para otimizar a eficiência no processo produtivo.

\section{CONCLUSÕES}

A identificação de unidades eficientes e ineficientes de forma relativa permitiu a definição da magnitude dessas eficiências ou ineficiências, revelando assim, alguns aspectos determinantes para a gestão em propriedades vitícolas.

Os produtores 2, 3, 10 e 11 são os que apresentam maior eficiência combinada dos fatores de produção, operam em escala ótima e por isso são considerados benchmarks. Pôde-se ainda observar que estas DMU's compõem a fronteira DEA-eficiente, correspondendo a $36 \%$ das propriedades analisadas. Cabe ressaltar que estas unidades produtivas alcançaram melhores resultados dado 0 conjunto de recursos disponíveis, com especificidade ao manejo da cultura e sistema de irrigação em quantidade suficiente.

As DMU's 4 e 6 apresentam excesso de insumos em função dos dados de produção apresentados e ambas as propriedades operam em escala supra-ótima, indicando desperdício. Neste sentido, oneram-se os custos de produção, haja vista que a maior quantidade utilizada dos insumos não resulta em melhorias na produtividade e consequente rentabilidade de quem produz.

Existem produtores com índice de eficiência muito baixo como a DMU 8, com menor eficiência técnica global, seguida da DMU 9 e 1. Para atingir a escala ótima de produção, tais propriedades devem reorganizar seus planejamentos no intuito de reduzir o uso de insumos, de maneira proporcional à produção obtida, em aproximadamente $74 \%, 66 \%$ e $40 \%$, respectivamente.

A elaboração deste trabalho foi apenas uma tentativa de estudar a técnica de Análise Envoltória de Dados, no que tange ao agronegócio aplicado à fruticultura regional, que vem se difundindo e atraindo pesquisadores das mais diversas áreas pelas suas características, e principalmente, pela eficiência obtida nos resultados. 


\section{REFERÊNCIAS}

AGRIANUAL 2014: Anuário da agricultura brasileira. São Paulo: Informa Economics South America/FNP, 2014. p. 463.

ALI, A. I.; SEIFORD, L. M. The Mathematical Programming Approach to Efficiency Analysis. In: FRIED, H. O.; LOVELL, C. A. K.; SCHIMIDT, S. S. (Orgs.). The measurement of productive efficiency: Techniques and Application. New York: Oxford University Press, 1993. cap. 3, p. 120-159.

ARZUBI, A.; BERBEL, J. Determinación de índices de eficiencia mediante DEA en explotaciones lecheras de Buenos Aires. Investigacion Agraria: Produccion y Sanidad Animales, v. 17, n. 1-2, p. 103-123, 2002.

BANKER, R. D.; CHARNES, A. E.; COOPER, W. W. Some Models for Estimating Technical and Scale Inefficiencies In: Data Envelopment Analysis. Management Science, v. 30, p. 1078-1092. 1984.

BOLIANI, A. C.; FRACARO, A. A.; CORRÊA, L. S. Uvas rústicas: cultivo e processamento em regiões tropicais. Jales-SP. 2008. p. 368.

BOLIANI, A. C.; CORRÊA, L. S. In: Simpósio Brasileiro sobre Uvas de Mesa. Ilha Solteira-SP, p. 17-25, 2001.

COELLI, T. J. A guide to DEAP version 2.1: a data envelopment analysis program. Armidale, Austrália: University of New England. 1996. p. 49.

CONCEIČÃO, M. A. F.; et al. Coeficiente de Cultura $(\mathrm{Kc})$ para videira com e sem Cobertura Vegetal no solo. Irriga, Botucatu, Edição Especial, p. 234-249, 2012.

CONCEIÇÃO, M. A. F.; TONIETTO, J. Clima vitícola para a região de Jales (SP). Bento Gonçalves: Embrapa Uva e Vinho, 2012. p. 32.

CONCEIÇÃO, M. A. F; MANDARINI NETO, J.; MAIA, J. D. G. Evapotranspiração da videira Niágara Rosada em Jales, SP. In: Congresso Brasileiro de Viticultura e Enologia, 9, Bento Gonçalves, 1999. Resumos... Bento Gonçalves: Embrapa Uva e Vinho, 1999.

COSTA, S. M. A. L.; GOMES, M. R. L.; TARSITANO, M. A. A. A comercialização de uvas finas na região de Jales (SP). Revista Brasileira de Fruticultura, v. 30, n. 1, p. 127-132, 2008.

COSTA, T. V.; TARSITANO, M. A. A.; CONCEIÇÃO, M. A. F. Caracterização social e tecnológica da produção de uvas para mesa em pequenas propriedades rurais da região de Jales (SP). Revista Brasileira de Fruticultura, v. 34, n. 3, p. 766-773, 2012.

DARILEK, J. L.; et al. Changes in soil fertility parameters and the environmental effects in a rapidly developing region of China. Agriculture, Ecosystems and Environment, Amstersam, v. 129, p. 286-292, 2009. 
FERREIRA, C. M. C.; GOMES, A. P. Introdução à análise envoltória de dados: Teoria, Modelos e Aplicações. Viçosa-MG: Editora UFV, 2012. p. 389.

FLYNN, I. M. Introdução aos sistemas operacionais. São Paulo: Editora Thompson, 2001.

GOMES, E. G.; MANGABEIRA, J. A. C.; MELLO, J. C. C. B. S. Análise de Envoltória de Dados para Avaliação de Eficiência e Caracterização de Tipologias em Agricultura: Um Estudo de Caso. Revista de Economia e Sociologia Rural (on line). 2005. V. 43, n. 4, p. 607-631.

HIGA, A. Viticultores de Jales buscam novos mercados. Estado de São Paulo, 4 fev. 2002.

IBGE. Instituto Brasileiro de Geografia e Estatística. Levantamento sistemático da produção agrícola - Banco SIDRA. Disponível em: <http://www.sidra.ibge.gov.br/bda/prevsaf/default.asp>. Acesso em: 10 dez. 2015.

IBGE. Instituto Brasileiro de Geografia e Estatística. Produção agrícola municipal 2014. Rio de Janeiro: IBGE, 2015. Disponível em: $<$ http://www.cidades.ibge.gov.br/xtras/perfil.php?lang=\&codmun=352480\&search=sa o-paulo|jales>. Acesso em: 06 Jun. 2016.

IEA. Instituto de Economia Agrícola. Estatísticas da produção paulista, disponível em <http://ciagri.iea.sp.gov.br/nia1/subjetiva.aspx?cod_sis=1\&idioma=1>. Acesso em: 01 out. 2015.

MAIA, J. D. G.; MELLO, L. M. R. Custos e rentabilidade. In: Cultivo da videira niágara rosada em regiões tropicais do Brasil. Embrapa Uva e Vinho - Sistemas de Produção, 5. Versão Eletrônica. 2003. Disponível em $<$ http://sistemasdeproducao.cnptia.embrapa.br/FontesHTML/Uva/UvaNiagaraRosada RegioesTropicais/custo.htm>. Acesso em: 01 nov. 2015.

MARCONI, M. A.; LAKATOS, E. M. Fundamentos de metodologia científica. 7. ed. - São Paulo: Atlas, 2010.

MELLO, J. C. C. B. S.; et al. Curso de Análise de Envoltória de Dados. XXXVII Simpósio brasileiro de pesquisa operacional. Gramado/RS, 2005. Disponível em <http://www.uff.br/decisao/sbpo2005_curso.pdf>. Acesso em: 04 dez. 2015.

MELLO, J. C. C. B. S.; et al. Análise de envoltória de dados no estudo da eficiência e dos benchmarks para companhias aéreas brasileiras. Pesquisa Operacional, v. 23, n. 2, p. 324-345, 2003.

MELLO, L. M. R. Relatório de avaliação de impactos do sistema de produção de uva niágara rosada em regiões tropicais. Empresa Brasileira de Pesquisa Agropecuária - EMBRAPA. Centro Nacional de Pesquisa de Uva e Vinho. Bento Gonçalves, $2015 \quad$ Disponível em: <http://bs.sede.embrapa.br/2014/relatorios/uvaevinho_2014_uva-niagara.pdf>. Acesso em: 15 out. 2015. 
NARDOQUE, S. Renda da terra e produção do espaço urbano em Jales - SP. 2007. Tese (Doutorado em Geografia) - Instituto de Geociências e Ciências Exatas/Universidade Estadual Paulista, 2007.

NETO, L. F. F.; et. al. As instituições no APL de uva de mesa da região de Jales SP sob a ótica da velha economia institucional. Encontro Nacional de Engenharia de Produção. Salvador-BA, p. 2, 2009.

PELINSON, G. J. B. A Importância da Viticultura na Região Noroeste do Estado de São Paulo. IN: BOLIANI, A. C.; CORRÊA, L. S. Simpósio Brasileiro sobre Uvas de Mesa. Ilha Solteira-SP, 2001.

PINHEIRO, M. E. F; ALTAFIN, I. G. Eficiência da produção familiar de leite em projetos de assentamento de reforma agrária: estudo multicaso. Organizações Rurais \& Agroindustriais, Lavras, v. 9, n. 2, p. 189-201, 2007.

REINALDO, R. R. P.; POSSAMAI, O.; THOMAZ, A. C. F. Avaliando a eficiência em unidades de ensino fundamental de Fortaleza usando técnicas de análise envoltória de dados (DEA). Revista Científica da Faculdade Lourenço Filho, v. 2, 2002. Disponível em <http://www.flf.edu.br/midias/FLF.EDU/21.pdf>. Acesso em: $10 \mathrm{dez}$. 2015.

SABBAG, O. J.; COSTA, S. M. A. L. Análise de custos da produção de leite: aplicação do método de Monte Carlo. Extensão Rural, Santa Maria, v. 22, n. 1, p. 125-145, 2015.

SÃO PAULO (Estado). Secretaria de Agricultura e Abastecimento. Coordenadoria de Assistência Técnica Integral. Instituto de Economia Agrícola. Levantamento censitário de unidades de produção agrícola do Estado de São Paulo - LUPA 2007/2008. São Paulo: SAA/CATI/IEA, 2008. Disponível em: <http://www.cati.sp.gov.br/projetolupa/dadosmunicipais/pdf/t281.pdf> Acesso em: 15 out. 2015.

SIMONETTI, D.; PERONDI, M. A.; KIYOTA, N.; VILLWOCK, A. P. S. Diversificação da renda e agregação de valor na agricultura familiar: lições a partir de uma comunidade rural. Extensão Rural, Santa Maria, v. 20, n. 2, p. 132-144, 2013.

SOUZA, P. C. T.; WILHELM, V. E. Uma introdução aos modelos DEA de eficiência técnica. Tuiuti: Ciência e Cultura, n. 42, p. 121-139, 2009.

SOUZA, J. S. I.; MARTINS, F. P. Viticultura brasileira: principais variedades e suas características. Piracicaba/SP: FEALQ, 2002. 